\title{
Produtividade, qualidade e estado nutricional da beterraba de mesa em função de doses de nitrogênio
}

\author{
Leonardo A de Aquino; Mário Puiatti; Paulo RG Pereira; Francisco HF Pereira; Igor R Ladeira; \\ Mariana RS Castro \\ UFV, Dep ${ }^{\text {to }}$ Fitotecnia 36570-000 Viçosa-MG; E-mail: aquinoufv@ yahoo.com.br
}

\begin{abstract}
RESUMO
O N é fundamental para a produtividade e a qualidade das hortaliças, todavia há carência de informações sobre seu uso em beterraba de mesa. Neste trabalho objetivou-se avaliar a produtividade, a qualidade e o estado nutricional nitrogenado da beterraba em função do $\mathrm{N}$ aplicado. Foram utilizadas quatro doses de N $(0 ; 100 ; 200$ e $400 \mathrm{~kg} \mathrm{ha}^{-1} \mathrm{de} \mathrm{N}$ ), no delineamento blocos casualizados, com quatro repetições. Aos 28 dias após o transplante (dat), avaliou-se o estado nutricional nitrogenado por meio do teor de $\mathrm{N}_{-} \mathrm{NO}_{3}^{-}$nas folhas e clorofilômetro (SPAD). Na colheita (56 dat), foram avaliados: área foliar, produção de massas fresca (MF) e seca (MS) e teores de $\mathrm{N}_{-} \mathrm{NO}_{3}^{-}$e N-total nas folhas e raizes tuberosas e de sólidos solúveis totais nas raizes tuberosas. Com o incremento das doses de $\mathrm{N}$, observaram-se aumentos para todas as características avaliadas. Aos 28 dias após o transplantio, o teor de $\mathrm{N}^{-} \mathrm{NO}_{3}^{-}$e unidades SPAD, correspondentes a $95 \%$ da produção máxima foram, respectivamente, de $2.575 \mathrm{mg} \mathrm{kg}^{-1}$ de MS e 44,7 unidades SPAD. Considerando-se apenas os aspectos quantitativo e econômico da produtividade de raizes, a dose de máxima eficiência econômica é de $343 \mathrm{~kg} \mathrm{ha}^{-1} \mathrm{de}$ $\mathrm{N}$; todavia, ao serem considerados os aspectos quantitativo e qualitativo, a dose recomendada é de $193 \mathrm{~kg} \mathrm{ha}^{-1}$ de N.
\end{abstract}

Palavras-chave: Beta vulgaris, adubação, clorofilômetro, nitrato, ${ }^{\circ}$ Brix.

\begin{abstract}
Yield, quality and nutritional status of table beet affected by nitrogen rates

Nitrogen is a fundamental element for the yield and quality of vegetables, but there is little information about its application to table beet crop. This work aimed to evaluate the yield, quality and nutritional status of $\mathrm{N}$ of the table beet as affected by the rate of $\mathrm{N}$. Four rates of nitrogen were applied $\left(0 ; 100 ; 200\right.$ and $\left.400 \mathrm{~kg} \mathrm{ha}^{-1} \mathrm{~N}\right)$ in a randomized block design with four replicates. 28 days after the transplant (dat), the nutritional $\mathrm{N}$ status was evaluated through the leaves content of $\mathrm{NO}_{3}^{-}-\mathrm{N}$ and chlorophyll by the SPAD meter. At harvest (56 dat), the traits evaluated were: leaf area, yield of fresh (FW) and dry weight (DW) of storage roots and leaves contents of $\mathrm{NO}_{3}^{-}-\mathrm{N}$ and total- $\mathrm{N}$ at the leaves, and storage roots and ${ }^{\circ} \mathrm{Brix}$ in the storage roots. With the increase of the doses of $\mathrm{N}$, all the selected characteristics were increased. The $\mathrm{NO}_{3}^{-}-\mathrm{N}$ and SPAD units at the 28 dat ( $95 \%$ of the maximum yield) were $2,575 \mathrm{mg} \mathrm{kg}^{-1}$ of DW and 44.7 , respectively. Considering the quantitative and economic aspects of the yield of storage roots, the rate of $343 \mathrm{~kg} \mathrm{ha}^{-1} \mathrm{~N}$ was the maximum economical efficiency rate. If considering the quantitative and qualitative aspects together, the $193 \mathrm{~kg} \mathrm{ha}^{-1}$ of $\mathrm{N}$ was the recommended rate.
\end{abstract}

Keywords: Beta vulgaris, fertilization, chlorophyll meters, nitrate, ${ }^{\circ}$ Brix.

\section{(Recebido para publicação em 26 de janeiro de 2006; aceito em 30 de maio de 2006)}

\begin{abstract}
A beterraba de mesa ou hortícola (Beta vulgaris $\mathrm{L}$. var. crassa) destaca-se, dentre as hortaliças, por sua composição nutricional, sobretudo em açúcares, e pelas formas de consumo da raiz tuberosa, além das folhas. A "raiz tuberosa", principal órgão armazenador de reservas, consiste do entumescimento do eixo hipocótilo-raiz e de porção superior limitada da raiz pivotante, e tem seu crescimento e composição influenciados pela adubação nitrogenada (Allison et al., 1996; Ugrinovic, 1999; Shock et al., 2000; Trani et al., 2005).

Além de constituinte de várias moléculas orgânicas, tais como proteínas, ácidos nucléicos e clorofilas, o nitrogênio exerce grande efeito no crescimento das plantas e na qualidade dos produtos vegetais (Marschner, 1995). Em beterraba açucareira, o $\mathrm{N}$ tem importante
\end{abstract}

efeito, tanto na produtividade quanto na qualidade das raizes, principalmente nos teores de açúcares e de $\mathrm{NO}_{3}^{-}$(Allison $e t$ al., 1996; Ugrinovic, 1999; Shock et al., 2000; Hoffmann \& Märländer, 2005).

O nitrogênio contribui para o aumento da produtividade das culturas por promover a expansão foliar e o acúmulo de massa. Todavia, energicamente, os processos fisiológicos na planta, que se estendem desde a absorção até a completa assimilação do $\mathrm{N}$ em moléculas orgânicas, são muito dispendiosos, razão pela qual doses elevadas de fertilizantes nitrogenados podem reduzir a produtividade (Marschner, 1995).

Correlação positiva entre massa fresca da parte aérea e produtividade tem sido constatada em tuberosas, entretanto essa afirmativa é verdadeira apenas dentro de certos limites, pois nem sem- pre crescimento de parte aérea é sinônimo de aumento em produtividade (Guimarães et al., 2002). Aumento da área foliar é benéfico para a produção até que o índice de área foliar atinja a máxima eficiência entre a interceptação da luz e conversão em reservas para crescimento; acima desse patamar, o efeito do auto-sombreamento torna-se expressivo, e a eficiência fotossintética das folhas inferiores do dossel torna-se baixa (Larcher, 2004).

$\mathrm{O}$ teor de $\mathrm{N}$ correlaciona-se positivamente com o teor protéico (Winzer $e t$ al., 1996; Shock et al., 2000; Sextom \& Carrol, 2002). Em beterraba açucareira, incrementos na dose de $\mathrm{N}$, dentro de certos limites, têm proporcionado aumentos na produção e nos teores de $\mathrm{N}$. Por outro lado, doses elevadas de N promoveram redução na concentração de 
açúcares em beterraba açucareira, repolho e cenoura, além do acúmulo de $\mathrm{N}$ $\mathrm{NO}_{3}^{-}$(Sextom \& Carrol, 2002). Em beterraba açucareira, o $\mathrm{N}$ em excesso pode incrementar compostos nitrogenados solúveis, os quais são indesejáveis por impedirem a recuperação do açúcar durante o processo de produção existindo, ainda, efeito ambiental e genotípico na concentração desses compostos (Hoffmann \& Märländer, 2005).

$\mathrm{Na}$ recomendação da adubação nitrogenada para hortaliças é importante considerar, além dos aspectos quantitativos, os aspectos qualitativos da produção, principalmente no tocante ao teor de $\mathrm{NO}_{3}^{-}$. Quando em grandes quantidades no organismo humano, o $\mathrm{NO}_{3}^{-}$pode ser convertido em $\mathrm{N}$-nitrosaminas, que são compostos potencialmente carcinogênicos, além de poder transformar a hemoglobina do sangue em f e r r i h m o g l o b i n a (metahemoglobinemia), impedindo o transporte de oxigênio dos alvéolos pulmonares para os tecidos (Rath et al., 1994; Hirondel \& Hirondel, 2001).

Em função do efeito marcante do $\mathrm{N}$ sobre a produtividade e qualidade das culturas, associado a lixiviação no perfil do solo e seu potencial de contaminação de reservas de águas (Mack, 1989; Olmedo et al., 1999), bem como do efeito carcinogênico do $\mathrm{NO}_{3}^{-}$no organismo humano (RATH et al., 1994; Hirondel \& Hirondel, 2001), pesquisas visando o estabelecimento de doses adequadas de adubação nitrogenada são de extrema importância para que a qualidade total seja alcançada no processo produtivo. Nesse contexto, a análise do estado nutricional permite ajustes nas doses de $\mathrm{N}$ a serem aplicadas de forma a se obter alta produtividade e qualidade e, ao mesmo tempo, minimizar a perda por lixiviação desse elemento no solo e os custos com fertilizantes nitrogenados (Fontes, 2001).

O estado nutricional nitrogenado é avaliado, tradicionalmente, por meio da análise foliar em determinado período da cultura, comparando-se determinada forma de $\mathrm{N}$ presente na planta com padrões de referência. Outra forma de avaliação se dá pelo teor de clorofila nas folhas (Minotti et al., 1994; Fontes et al., 1997), que pode ser estimado indi- retamente pela intensidade da cor verde (unidades SPAD) medida em clorofilômetros (Fontes, 2001).

A aplicabilidade do uso dos clorofilômetros para diagnóstico em tempo real do estado nutricional nitrogenado tem sido demonstrada nas culturas da batata (Minotti et al., 1994), alface (Fontes et al., 1997) e beterraba açucareira (Sexton \& Carroll, 2002). No entanto, Sexton \& Carroll (2002) observaram que as unidades SPAD não representavam adequadamente o estado nutricional nitrogenado da cultura da beterraba açucareira quando a disponibilidade de $\mathrm{N}$ era muito alta. Portanto, a eficiência do diagnóstico do estado nutricional nitrogenado com os clorofilômetros exige calibração de acordo com a cultura e condições edafoclimáticas de cultivo. Nas condições brasileiras, há carência de trabalhos correlacionando unidades SPAD com o estado nutricional nitrogenado e produtividade da beterraba de mesa, bem como do manejo da adubação nitrogenada sobre aspectos qualitativos da produção.

Objetivou-se, com esse trabalho, avaliar o efeito de doses de N sobre a produtividade, a qualidade e o estado nutricional nitrogenado da beterraba de mesa, visando gerar subsídios para recomendação de doses de N para a cultura.

\section{MATERIAL E MÉTODOS}

O experimento foi conduzido a campo, na Universidade Federal de Viçosa, no período de abril a julho de 2003 . Utilizou-se a beterraba 'Early Wonder 2000', sendo as mudas transplantadas com 4 a 5 folhas definitivas, aos 39 dias após a semeadura. As mudas foram produzidas em sementeira, a céu aberto, em leito de terra enriquecida com esterco de gado curtido na proporção de 2:1 (terra:esterco); o solo da área de cultivo é classificado como Argissolo Vermelho Amarelo, textura argilosa. O substrato do leito de sementeira e o solo de cultivo apresentaram nas análises químicas, respectivamente, os seguintes valores: $\mathrm{pH}$ em $\mathrm{H}_{2} \mathrm{O}$ (relação $1: 2,5$ )= 6,5 e 6,$3 ; \mathrm{P}=159$ e $45 \mathrm{mg} \mathrm{dm}^{-3} ; \mathrm{K}=270$ e $117 \mathrm{mg} \mathrm{dm}^{-3}$ (P-K: extrator Mehlich 1); $\mathrm{Ca}^{2+}=60$ e $39 \mathrm{mmol}_{\mathrm{c}} \mathrm{dm}^{-3} ; \mathrm{Mg}^{2+}=10$ e $8 \mathrm{mmol}_{\mathrm{c}} \mathrm{dm}^{-3}$ (Ca e $\mathrm{Mg}$ : extrator $\mathrm{KCl}$ $\left.1 \mathrm{~mol} \mathrm{~L}^{-1}\right) ; \mathrm{H}+\mathrm{Al}=23$ e $23 \mathrm{mmol}_{\mathrm{c}} \mathrm{dm}^{-3}$ (extrator acetato de cálcio $0,5 \mathrm{~mol} \mathrm{~L}^{-1} \mathrm{a}$ $\mathrm{pH} 7,0) ; \mathrm{SB}=77$ e $50 \mathrm{mmol}_{\mathrm{c}} \mathrm{dm}^{-3} ; \mathrm{V}=$ 77 e $68 \% ; \mathrm{m}=0$ e $0 \%$ e $\mathrm{M} . \mathrm{O}=32$ e $19 \mathrm{~g}$ $\mathrm{kg}^{-1}$. Na área de cultivo haviam sido realizados, anteriormente à instalação do experimento, cultivos sucessivos com milho, sem fertilização, objetivando reduzir, sobretudo, os teores de $\mathrm{N}$ do solo.

Os tratamentos constituíram-se de quatro doses de $\mathrm{N}(0,100,200$ e $400 \mathrm{~kg}$ ha $^{-1}$ de N), distribuídos no delineamento experimental de blocos casualizados, com quatro repetições. Utilizou-se canteiros de $20 \mathrm{~cm}$ de altura, com $1 \mathrm{~m}$ de largura, contendo quatro fileiras longitudinais distanciadas de $20 \mathrm{~cm}$ e as plantas distanciadas, entre si na fileira, de $10 \mathrm{~cm}$. A parcela experimental consistiu de um canteiro com 2 m comprimento; considerando como útil a área compreendida pelas duas fileiras centrais do canteiro, excetuando-se 0,30 $\mathrm{m}$ das extremidades. Em parte da parcela (30\%) procedeu-se coleta de plantas aos 28 dat para avaliação do estado nutricional nitrogenado; sendo que na parte restante $(70 \%)$, procedeu-se a colheita para avaliação da produtividade aos 56 dat.

O preparo do solo constou de aração, passagem de rotoencanteirador e abertura manual dos sulcos de plantio. Exceto para o $\mathrm{N}$, as adubações foram realizadas com base na análise química de amostra do solo e recomendações para a cultura no estado de Minas Gerais (Ribeiro et al., 1999). Na adubação de plantio os nutrientes foram distribuídos e incorporados nos sulcos dois dias antes do transplante das mudas, nas seguintes quantidades: $240 \mathrm{~kg} \mathrm{ha}^{-1} \mathrm{de}_{2} \mathrm{O}_{5}$; $54 \mathrm{~kg} \mathrm{ha}^{-1}$ de $\mathrm{K}_{2} \mathrm{O}$ e $30 \%$ da dose total de $\mathrm{N}$ de cada tratamento; utilizou-se, como fonte, superfosfato simples, cloreto de potássio e uréia, respectivamente. Aplicou-se ainda, no plantio, o equivalente a $15 \mathrm{~kg} \mathrm{ha}^{-1}$ de sulfato de zinco, $10 \mathrm{~kg} \mathrm{ha}^{-1}$ de bórax, $10 \mathrm{~kg} \mathrm{ha}^{-1} \mathrm{de}$ sulfato de cobre e $0,5 \mathrm{~kg} \mathrm{ha}^{-1} \mathrm{de}$ molibdato de amônio. Aos 20 e 31 dat, foram realizadas adubações de cobertura com $\mathrm{N}$ e $\mathrm{K}$ sendo aplicadas, em cada uma, $35 \%$ das doses totais de $\mathrm{N}$ e $63 \mathrm{~kg}$ $\mathrm{ha}^{-1}$ de $\mathrm{K}_{2} \mathrm{O}$.

Durante a condução do experimento realizou-se uma capina manual aos 
25 dat e uma pulverização à base de oxicloreto de cobre para controle da mancha de cercóspora (Cercospora beticola). As irrigações foram realizadas por aspersão convencional, e as lâminas aplicadas de acordo com recomendação para a cultura, conforme Oliveira \& Tagliaferre (2005).

Aos 28 dat foi estimado o teor de clorofila, utilizando-se clorofilômetro portátil (SPAD 502, Minolta), procedendo-se a leitura na segunda folha completamente expandida, do ápice para a base, em seis plantas da parcela. A seguir, essas plantas foram coletadas, entre 15 h e 17 h e a parte aérea, após lavada e enxuta, foi seca em estufa com ventilação forçada de ar a $65^{\circ} \mathrm{C}$, até que se alcançasse massa constante. Após trituradas, porções de $0,1 \mathrm{~g}$ de massa seca (MS) foram utilizadas para determinação do teor de $\mathrm{N}_{-} \mathrm{NO}_{3}^{-}$para diagnose do estado nutricional nitrogenado, conforme Cataldo et al. (1975).

Aos 56 dat procedeu-se a colheita para avaliação da produtividade. Parte aérea (folhas) e "raiz tuberosa" de todas as plantas na parte restante da parcela útil foram pesadas para obtenção da massa fresca (MF). Parte aérea e raizes tuberosas de seis plantas de cada parcela, foram lavadas e colocadas para secar (como aos 28 dat), para determinação da MS e dos teores na MS de N$\mathrm{NO}_{3}^{-}$(Cataldo et al., 1975) e de N-total (Bremer, 1965). Em outras seis plantas avaliou-se a área foliar e o teor de sólidos solúveis totais $\left({ }^{\circ} \mathrm{Brix}\right)$ na raiz tuberosa. A área foliar foi obtida em integrador de área foliar (Licor Area Meter 3100), e o teor de sólidos solúveis em refratômetro portátil (Minolta), utilizando suco extraído pela compressão de uma fatia de cerca de $3 \mathrm{~mm}$ de espessura retirada na porção equatorial da raiz tuberosa.

Os dados obtidos foram submetidos à análise de variância e, quando esta acusou diferenças significativas $(\mathrm{P}<0,05)$, foram submetidos à regressão utilizando-se o programa estatístico SAEG (Ribeiro júnior, 2001). As doses de máxima eficiência econômica, para a produtividade de massa fresca de folhas e de raizes tuberosas, foram determinadas de acordo com a cotação do produto na CEASA-MG à época da co-
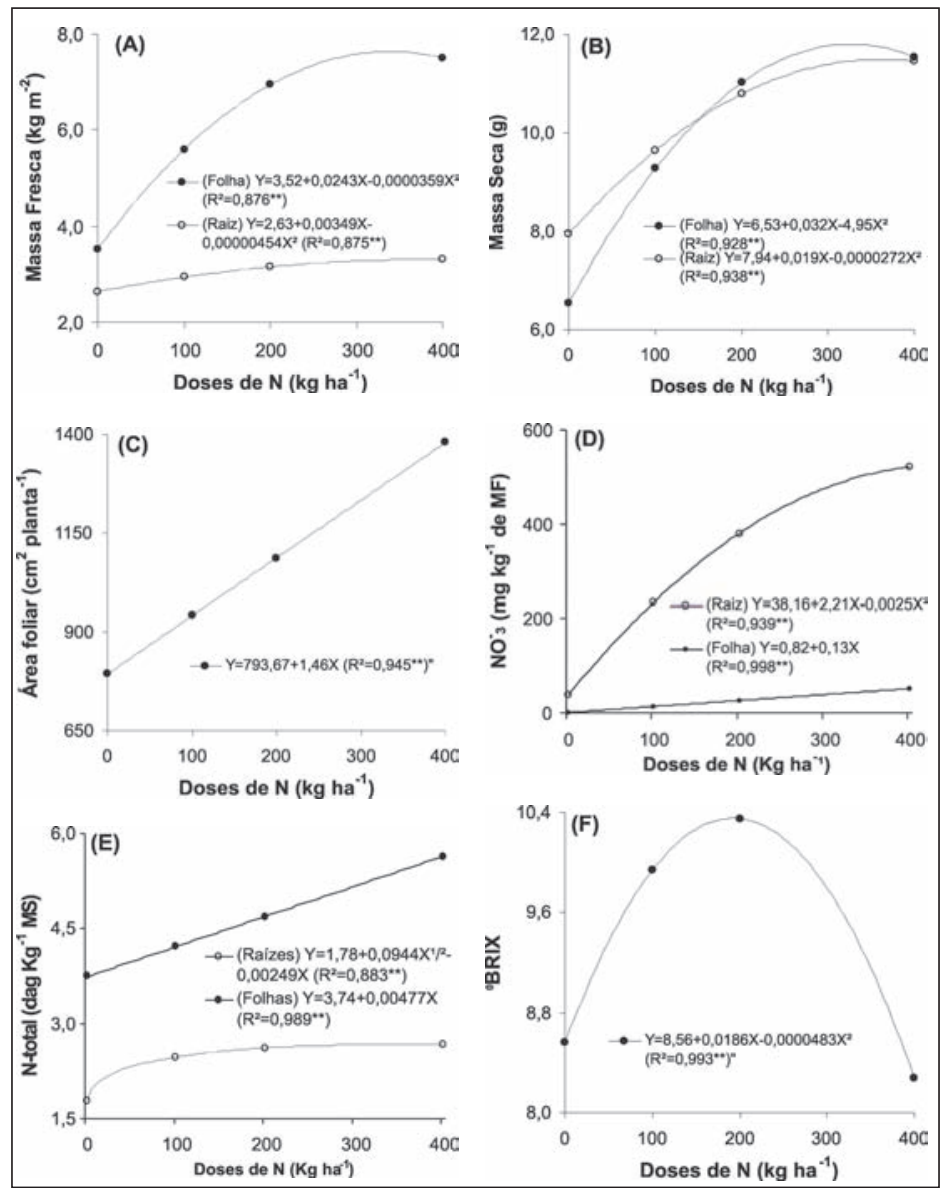

Figura 1. Produção de massas fresca (A) e seca (B) de raizes e folhas, área foliar (C), teores de N-NO- ${ }_{3}^{-}$(D) e N-total (E) nas raizes tuberosas e folhas, e de ${ }^{\circ}$ Brix (F) na raíz tuberosa da beterraba 'Early Wonder 2000', na colheita, aos 56 dias após transplante, em função de doses de N. Viçosa, UFV, 2003.

lheita e o custo do fertilizante nitrogenado praticado em lojas de produtos agropecuários à época do plantio (Fontes, 2001).

\section{RESULTADOS E DISCUSSÃO}

$\mathrm{O}$ aumento da dose de $\mathrm{N}$ promoveu incrementos, até certo ponto, em todas as características avaliadas (Figuras 1 e 2). As produtividades máximas estimadas de massa fresca de raizes tuberosas (MFR) e de folhas (MFF) foram de 3,30 e 7,63 $\mathrm{kg} \mathrm{m}^{-2}$, obtidas com as doses de 384 e $338 \mathrm{~kg} \mathrm{ha}^{-1}$ de $\mathrm{N}$, respectivamente (Figura 1A); as doses de máxima eficiência econômica (DMEE) para MFR e de MFF foram 343 e $331 \mathrm{~kg} \mathrm{ha}^{-1}$ de N, respectivamente. Os máximos estimados para produtividade de massa seca de raiz tuberosa (MSR) de 11,49 g plan$\mathrm{ta}^{-1}$, e de folhas (MSF) de 11,83 g plan$\mathrm{ta}^{-1}$ foram obtidos com as doses de 361 e $326 \mathrm{~kg} \mathrm{ha}^{-1}$ de N, respectivamente (Figura 1B). As produtividades de $\mathrm{MF}$ e de MS de raiz e de folha apresentaram incrementos decrescentes nas doses mais elevadas de $\mathrm{N}$, comportamento também observado em beterraba açucareira por Allison et al. (1996) e Shock et al. (2000), e por Trani et al. (2005) em raiz tuberosa de beterraba de mesa. Todavia, Trani et al. (2005) encontraram incrementos lineares na pro- 


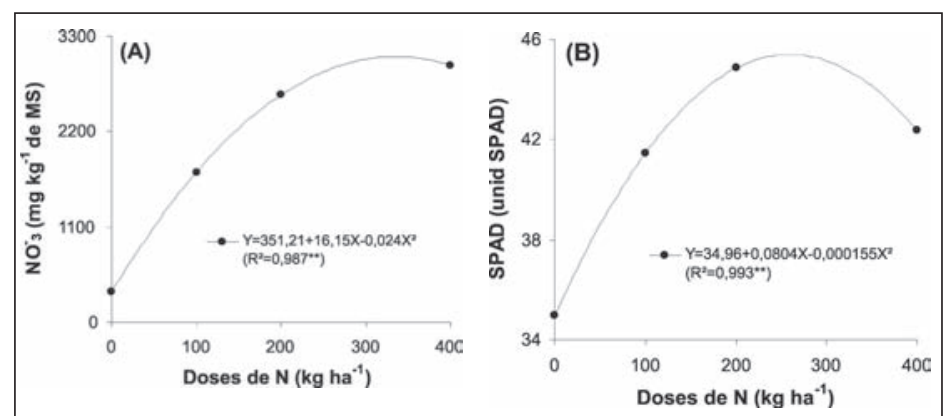

Figura 2. Teor de $\mathrm{N}^{-N^{-}}{ }_{3}$ (A) e unidades SPAD (B) em folhas de beterraba 'Early Wonder 2000' aos 28 dias após transplante, em função de doses de N. Viçosa, UFV, 2003.

dução de parte aérea de beterraba de mesa com aumentos nas doses de sulfato de amônio até a dose de $200 \mathrm{~kg} \mathrm{ha}^{-1}$ de N.

Contrastando com as características anteriores, a área foliar (AF) apresentou resposta linear ao incremento da dose de $\mathrm{N}$ aplicada (Figura 1C), semelhantemente ao observado por Trani et al. (2005) para produtividade de massa de folha. Visto que a produtividade de MSF apresentou ponto de máxima produtividade dentro do limite das doses de $\mathrm{N}$ estudadas (Figura 1B), pode-se inferir que doses elevadas de $\mathrm{N}$ estimularam mais o crescimento das folhas em expansão, promovendo aumento da área foliar específica (AF/ MSF), em detrimento do crescimento da raiz tuberosa. Esses resultados evidenciam que, até certo limite, incrementos na disponibilidade de $\mathrm{N}$ às plantas de beterraba de mesa promovem aumento da $\mathrm{AF}$ resultando, em contra partida, em aumento da produtividade de raiz tuberosa, confirmando observações de Allison et al. (1996) e Ugrinovic (1999) em beterraba açucareira e de Cardoso $\&$ Hiraki (2001) em rabanete. Entretanto, após certo limite, incrementos na AF não são acompanhados de maneira proporcional por incrementos de massa da raiz tuberosa, provavelmente devido ao auto-sombreamento decorrente do aumento excessivo do índice de área foliar (Larcher, 2004).

Nas folhas analisadas aos 28 dat observou-se aumento no teor de $\mathrm{N}_{-} \mathrm{NO}_{3}^{-} \mathrm{e}$ das unidades SPAD, com incremento na dose de $\mathrm{N}$ (Figura 2), com teor máximo de $\mathrm{N}_{-} \mathrm{NO}_{3}^{-}$estimado de $3.068 \mathrm{mg} \mathrm{kg}^{-1}$ de MS, obtido com a dose de $336 \mathrm{~kg}$ ha-
${ }^{1}$ de $\mathrm{N}$ (Figura 2A), enquanto que o teor de $\mathrm{N}^{-N^{-}}{ }_{3}$ correspondente as DMEE para MFR e MFF foi de $3.066 \mathrm{mg} \mathrm{kg}^{-1}$ de MS. No que concerne ao potencial carcinogênico do $\mathrm{NO}_{3}^{-}$em hortaliças, os valores máximos tolerados para alface e espinafre na Comunidade Européia e na Polônia variam, respectivamente, de 2000-4500 e de 250-2000 mg NO${ }_{3}^{-} \mathrm{kg}^{-1}$ de massa fresca (Hirondel \& Hirondel, 2001).

A leitura máxima estimada do clorofilômetro de 45,4 unidades SPAD, obtida com a dose de $259 \mathrm{~kg} \mathrm{ha}^{-1}$ de $\mathrm{N}$ (Figura 2B), indica que o uso do clorofilômetro não é um método eficiente para proceder o diagnóstico do estado nutricional nitrogenado em beterraba de mesa visto que, em determinado intervalo, leitura abaixo de 45,4 poderia estar representando tanto a faixa adequada como a inadequada de $\mathrm{N}$ na folha, confirmando observações de Sextom \& Carroll (2002) em beterraba açucareira. Por outro lado, considerando a DMEE como sendo àquela que proporciona $95 \%$ da produtividade proporcionada pela dose de máxima eficiência fisiológica (Fontes, 2001), o uso do clorofilômetro para diagnóstico do estado nutricional nitrogenado torna-se mais representativo. Neste caso, aos 28 dat, as unidades SPAD correspondente à dose de $193 \mathrm{~kg} \mathrm{ha}^{-1}$ de N (95\% dose de máxima eficiência fisiológica), foi de 44,7 , correspondendo ao teor estimado de $\mathrm{N}^{-N^{-}}{ }_{3}$ de $2.575 \mathrm{mg} \mathrm{kg}^{-1}$ de MS.

$\mathrm{Na}$ colheita (56 dat), observou-se aumento nos teores de $\mathrm{N}^{-\mathrm{NO}^{-}}{ }_{3}$ nas folhas e raizes tuberosas, com o incremento da dose de N, sendo esse proporcionalmente maior nas raizes tuberosas do que nas folhas (Figura 1D). Tal comportamento evidencia que, na beterraba de mesa 'Early Wonder, 2000' a redução do $\mathrm{NO}_{3}^{-}$ocorre preferencialmente nas folhas. Outra evidência da limitada assimilação do $\mathrm{N}$ nas raizes é verificada ao se comparar os teores de $\mathrm{N}$-total nas folhas e nas raizes tuberosas (Figura 1E). A redução do $\mathrm{NO}_{3}^{-}$é energeticamente muito dispendiosa e limitada na raiz, razão pela qual, em muitas espécies vegetais, o nitrato é translocado para a parte aérea, onde é reduzido e incorporado em moléculas orgânicas (Marschner, 1995).

Os teores máximos estimados de $\mathrm{N}$ $\mathrm{NO}_{3}^{-}$nas folhas e raizes tuberosas aos 56 dat, foram de 52,82 e $522 \mathrm{mg} \mathrm{kg}^{-1}$ de MF, respectivamente. Países com legislação rígida no que concerne ao potencial carcinogênico do $\mathrm{NO}_{3}^{-}$em hortaliças, como a Polônia, estabelecem limites aceitáveis para alface e espinafre de 250-2000 $\mathrm{mg} \mathrm{NO}_{3}{ }^{-} \mathrm{kg}^{-1}$ de massa fresca (Hirondel \&Hirondel, 2001).

Nas folhas verificou-se aumento linear no teor de $\mathrm{N}$-total com o incremento da dose de $\mathrm{N}$, enquanto que nas raizes tuberosas o teor de $\mathrm{N}$-total praticamente não se alterou a partir de $100 \mathrm{~kg} \mathrm{ha}^{-1} \mathrm{de}$ N (Figura 1E). Trani et al. (2005) observaram aumento linear dos teores de $\mathrm{N}$ total tanto da raiz como na parte aérea. Tal diferença pode ser explicada pelas diferenças das cultivares utilizadas nos trabalhos e dos fatores edafoclimáticos, que influenciam a resposta da beterraba ao N (Trani et al., 1993).

Os teores máximos estimados de $\mathrm{N}$ total nas raizes e nas folhas foram de 2,7 e 5,7 dag kg-1 de MS, respectivamente, obtidos com a maior dose de N. Shock et al. (2000) em beterraba açucareira e Trani et al. (2005) em beterraba de mesa também observaram maior teor de $\mathrm{N}$-total nas folhas do que nas raizes, apesar dos teores de $\mathrm{N}$-total serem menores que os observados neste trabalho. Shock et al. (2000) \& Trani et al. (2005) obtiveram, respectivamente, valores variando de 2,0 a 3,0 e de 2,7 a $3,7 \mathrm{dag} \mathrm{kg}^{-1}$ nas folhas e de 0,9 a $1,3 \mathrm{e}$ de 1,8 a 2,7 dag $\mathrm{kg}^{-1}$, nas raizes tuberosas. $\mathrm{O}$ teor de $\mathrm{N}$ obtido nesse trabalho na parte aérea foi superior àquele obtido por Trani et al. (2005), enquanto que teor de $\mathrm{N}$ na raiz tuberosa não se 
distanciou muito do valor observado por esses autores.

Considerando o aumento proporcionalmente maior do teor de $\mathrm{N}$-total nas folhas do que nas raizes, doses mais elevadas de $\mathrm{N}$, desde que não permitam acúmulo excessivo de $\mathrm{N}_{-} \mathrm{NO}_{3}^{-}$nas folhas, poderiam contribuir para aumentar o teor protéico nas folhas, porém não nas raizes. Isso é interessante no caso de comercialização da planta toda (molhos) caso em que as folhas também são utilizadas na alimentação.

Diferenças no teor de N-total podem ser atribuídas a materiais cultivados, visto que Winzer et al. (1996) verificaram que, sob fertilização nitrogenada, beterrabas de mesa acumulam mais íons e menos açúcares que as beterrabas açucareiras. Hoffmann e Märländer (2005) também verificaram diferenças genotípicas e ambientais em beterraba açucareira quanto à concentração de compostos nitrogenados solúveis.

O teor de sólidos solúveis totais $\left({ }^{\circ}\right.$ Brix) nas raizes tuberosas apresentou aumento com o incremento da dose de $\mathrm{N}$ até a dose de $193 \mathrm{~kg} \mathrm{ha}^{-1}$ de $\mathrm{N}$, com ${ }^{\circ}$ Brix máximo estimado de 10,4, havendo significativa redução a partir dessa dose (Figura 1F). O ${ }^{\circ}$ Brix oferece boa estimativa do conteúdo de açúcares no tecido vegetal, que se constitui em importante característica qualitativa para a beterraba. Winzer et al. (1996) também observaram, dentro de certos limites, aumento no teor de sacarose em beterraba com o aumento da disponibilidade de $\mathrm{N}$.

O limite para aumento do conteúdo de açúcares pode advir, dentre outros fatores, do elevado custo energético para redução do $\mathrm{N}^{-\mathrm{NO}_{3}^{-}}$e incorporação do N$\mathrm{NH}_{4}^{+}$em moléculas orgânicas; do excessivo estímulo à parte aérea pelo $\mathrm{N}$, fazendo com que essa tenha considerável força dreno, comparativamente à raiz; e do efeito osmótico do $\mathrm{NO}_{3}^{-}$, fazendo que haja diluição dos açúcares translocados para a raiz (Marschner, 1995), haja visto o maior acúmulo de $\mathrm{N}_{-} \mathrm{NO}_{3}^{-}$na raiz tuberosa (Figura 1D). Em beterraba açucareira o $\mathrm{N}$ em excesso também pode incrementar compostos nitrogenados solúveis, os quais impedem a recuperação do açúcar durante o processo de produção (Hoffmann \& Märländer, 2005).
Ao serem considerados apenas os aspectos quantitativo e econômico da produção de raizes tuberosas (MFR), a dose de $343 \mathrm{~kg} \mathrm{ha}^{-1}$ de N (DMEE) pode ser indicada. Por outro lado, se considerar além da produção de MFR também o aspecto qualitativo $\left(\mathrm{N}^{-\mathrm{NO}_{3}^{-}} \mathrm{e}\right.$ ${ }^{\circ}$ Brix), a dose de $193 \mathrm{~kg} \mathrm{ha}^{-1}$ de $\mathrm{N}$, deve ser recomendada; com essa dose se obtêm alto ${ }^{\circ}$ Brix da raiz tuberosa sem, conduto, haver acúmulo de $\mathrm{N}^{-\mathrm{NO}_{3}^{-}}$em níveis elevados. Essa dose está bem abaixo da DMEE para produtividade de MFR, porém, em virtude das exigências do consumidor quanto à qualidade dos alimentos, especialmente em termos de

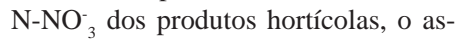
pecto qualitativo não deve ser menosprezado. Assim, a dose de $193 \mathrm{~kg} \mathrm{ha}^{-1}$ de N, para o cultivo de beterraba de mesa no período de outono seria mais recomendável. Para tal, as unidades SPAD e teor de ${\mathrm{N}-\mathrm{NO}_{3}^{-}}_{3}$ aos 28 dat, correspondentes a dose de máxima qualidade seria 44,7 e $2.575 \mathrm{mg} \mathrm{kg}^{-1}$ de MS, respectivamente.

\section{AGRADECIMENTOS}

Os autores agradecem ao CNPq pela bolsa de IC concedida ao primeiro autor do trabalho.

\section{REFERÊNCIAS}

ALLISON MF; ARMSTRONG MJ; JAGGARD KW; TODD AD; MILFORD GFJ. 1996. An analysis of the agronomic, economic, and environmental effects of applying $\mathrm{N}$ fertilizer to sugarbeet (Beta vulgaris). Journal of Agricultural Science, Cambridge 127: 475-486.

BREMNER JM. 1965. Total nitrogen. In: BLACK CA (eds). Methods of soil analysis. Madison: American Society of Agronomy. part 2. p. 1149-1178.

CARDOSO AII; HIRAKI H. 2001. Avaliação de doses e épocas de aplicação de nitrato de cálcio em cobertura na cultura do rabanete. Horticultura Brasileira 19: p. 328-331.

CATALDO DA; HAROON M; SCHARDER M; YOUNGS VL. 1975. Rapid colorimetric of nitrate in plant tissue by nitrification of salicylic acid. Communication Soil Science Plant Analyses 6: 71-81.

FONTES PCR. 2001. Diagnóstico do estado nutricional das plantas. Viçosa: UFV. 122p.

FONTES PCR, PEREIRA PRG, CONDE RM. 1997. Critical chlorophyll, total $\mathrm{N}$, and $\mathrm{NO}_{3}^{-}$ $\mathrm{N}$ in leaves associated to maximum lettuce yield. Journal of Plant Nutrition 20: 10611068.
GUIMARÃES VF; ECHER MM; MINAMI K. 2002. Métodos de produção de mudas, distribuição de matéria seca e produtividade de plantas de beterraba. Horticultura Brasileira 20: 505-509.

HIRONDEL JI; HIRONDEL JL. 2001. Nitrate and man: toxic, harmless or beneficial? New York: CAB Publishing. 168p.

HOFFMANN CM; MÄRLÄNDE B. 2005. Composition of harmful nitrogen in sugar beet (Beta vulgaris $\mathrm{L}$.) amino acids, betaine, nitrate as affected by genotype and environment. European Journal of Agronomy 22: 255-265.

LARCHER W. 2004. Ecofisiologia vegetal. São Carlos: Rima Artes e Textos. 531p.

MACK HJ. 1989. Effects of nitrogen, boron and potassium on deficiency, leaf mineral concentrations, and yield of table beets (Beta vulgaris L.). Communications In Soil Science Plant Analysis 20: 291-303.

MARSCHNER H. 1995. Mineral nutrition of higher plant. 2.ed. N. York: Ac. Press. 889p.

MINOTTI PL, HALSETH DE, SIECZKA JB. 1994. Field chlorophyll measurements to asses the $\mathrm{N}$ status of potato varieties. HortScience 29: 1497-1500.

OLIVEIRA RA; TAGLIAFERRE C. 2005. Manejo da irrigação. In: FONTES PCR (eds). Olericultura: teoria e prática. Viçosa: UFV. p. 143-158.

OLMEDO PM; MURILLO JM; CABRERA F; LÓPEZ R. 1999. Sugarbeet (Beta vulgaris) response to residual soil $\mathrm{N}$ under Mediterranean agronomic practices. Journal of Agricultural Science 132: 273-280.

RATH S; XIMENES MIN; REYES FGR. 1994. Teores de nitrato e nitrito em vegetais cultivados no Distrito Federal: um estudo preliminar. Revista Instituto Adolfo Lutz 54: 126-130.

RIBEIRO JÚNIOR IR. 2001. Análises estatísticas no SAEG. Viçosa: UFV. 301p.

RIBEIRO AC, GUIMARÃES PTG, ALVAREZ VVH. 1999. Recomendação para uso de corretivos e fertilizantes em Minas Gerais-5 ${ }^{\text {a }}$ Aproximação, CFSEMG. Viçosa: UFV. 359p.

SEXTON P; CARROL J. 2002. Comparison of SPAD chlorophyll meter readings vs. petiole nitrate concentration in sugarbeet. Journal of Plant Nutrition 25: 1975-1986.

SHOCK CC; SEDDIGH M; SAUNDERS LD; STIEBER TD; MILLER J. 2000. Sugarbeet nitrogen uptake and performance following heavily fertilized onion. Agronomy Journal 92 : 10-15.

TRANI PE; FORNASIER JB; LISBÃO RS. 1993. Nutrição mineral e adubação da beterraba. In: FERREIRA ME; CASTELLANE PD; CRUZ MCP (eds). Nutrição e adubação de hortaliças. Piracicaba: Associação Brasileira para Pesquisa da Potassa e do Fosfato. p. 429-446.

TRANI PE; CANTARELLA H; TIVELLI SW. 2005. Produtividade de beterraba em função de doses de sulfato de amônio em cobertura. Horticultura Brasileira 23: 726-730.

UGRINOVIC K. 1999. Effect of nitrogen fertilization on quality and yield of red beet (Beta vulgaris var. conditiva Alef.). Acta Horticulturae 506: 99-104.

WINZER T; LOHAUS G; HELDT HW. 1996. Influence of phloem transport, $\mathrm{N}$-fertilization and ion accumulation on sucrose in the taproots fodder beet and sugar beet. Journal of Experimental Botany 47: 863-870. 